\title{
Specialist sexual violence social work: Ensuring good practice
}

Bridget Leary, Social Worker in the Sexual Violence Field, Wellington, New Zealand

Dr Kathryn Hay, School of Social Work, Massey University, New Zealand

\begin{abstract}
INTRODUCTION: This research sought to understand social workers' perspectives on good practice in specialist sexual violence social work practice in Aotearoa New Zealand.
\end{abstract}

METHODS: In 2018, five registered social workers engaged in semi-structured interviews focused on good practice social work in the field of sexual violence.

FINDINGS: The use of therapeutic social work, along with an extensive skill set and knowledge base were identified as fundamental for sexual violence social work. Boundaries and the development of broad self-care practices were recognised as crucial components of good practice.

CONCLUSIONS: The findings from this study offers links between the field of sexual violence and social work practice, while also indicating the need for future research.

KEYWORDS: Social work; sexual violence; Aotearoa New Zealand; good practice

\section{AOTEAROA}

NEW ZEALAND SOCIAL WORK 31(4), 60-71.

CORRESPONDENCE TO: Dr Kathryn Hay

k.s.hay@massey.ac.nz
Sexual violence is a widespread issue both internationally and in Aotearoa New Zealand with severe and extensive consequences (Mason \& Lodrick, 2013; Mossman, Jordan, MacGibbon, Kingi, \& Moore, 2009; Thorburn, 2015). It is estimated that one in three females and one in seven males in Aotearoa New Zealand have experienced sexual violence (Fanslow, Robinson, Crengle, \& Perese, 2007; Ministry of Women's Affairs, 2012; Mortimer et al., 2009; Thorburn, 2015). Māori women are nearly twice as likely to experience sexual violence as the general population, with Pacific and migrant women also at greater risk (Mayhew \& Reilly, 2009).

While sexual violence social work in Aotearoa New Zealand has traditionally functioned as support work with a focus on short-term, practical guidance, there has been a move toward comprehensive, therapeutic practice. There is a need for informed and appropriate intervention in cases of sexual violence due to the high and complex needs of people who are affected (Ministry of Women's Affairs, 2009; Mossman, Jordan et al., 2009; Thorburn, 2015). If individuals impacted by sexual violence are not attended to by specialised professionals, it can be detrimental to their ongoing well-being with individuals being re-traumatised throughout their disclosures and subsequent healing journeys (Campbell, Wasco, Ahrens, Sefl, \& Barnes, 2001). People who experience sexual violence often have interaction with social workers and therefore, having a social worker who 
is specifically trained in a sexual violence scope of practice may aid in the reduction of re-traumatisation (Mason \& Lodrick, 2013; Thorburn, 2015).

This article draws on findings from a study that explored good practice social work in the field of sexual violence from the perspectives of five registered social workers. The study was a supervised research project completed as part of a master's degree in applied social work through Massey University. The focus of this article is to link the profession of social work to the field of sexual violence in Aotearoa New Zealand and stimulate a discussion on the practice of social work in this specialist area.

\section{Literature review}

In 2009, the Ministry of Women's Affairs in Aotearoa New Zealand conducted research on effective interventions within the field, including a literature review on good practice (Mossman, Jordan et al., 2009). This literature review provided information on good practice within the medical system, the mental health system, the criminal justice system and support services in regard to sexual violence (Mossman, Jordan et al., 2009). Then, in 2016, Te Ohaaki a Hine National Network Ending Sexual Violence Together (TOAHNNEST) worked to modernise existing good practice guidelines based on practice evidence. These guidelines outline 15 principles for good practice in mainstream crisis support services within the sexual violence field (Wharewera-Mika \& McPhillips, 2016). Another piece of research from Aotearoa New Zealand is a research report completed with the support of Aviva Family Violence Services, START, and the Ministry of Social Development by Dr Lesley Campbell to inform the service design of a sexual assault support service in Canterbury (Campbell, 2016).

While these examples of research have focused on the field of sexual violence in Aotearoa New Zealand, there has not been an in-depth, specific exploration of good practice for social workers engaged in this domain. Also, most international research has thus far focused on the work of psychiatrists, psychologists, counsellors and crisis workers, leaving limited links to social workers (Mortimer et al., 2009; Murphy et al., 2011). While the reviewed studies may not focus primarily on social work, they outline factors that share similarities to social work skills, knowledge and values, as well as the potential impacts of sexual violence work on the social work professional.

\section{Skills}

The most commonly expressed professional skills necessary for social work practice in the sexual violence field include counselling, listening, advocacy, and managing the tensions of one's world view within professional practice. The personal attributes of empathy and holding belief in the client are also highlighted. Jordan (2008) observes that there are positive impacts for people who experience sexual violence when professionals employ acceptance and empathy while hearing a client's story. Similarly, Thorburn (2015) points out the importance of empathy, listening skills and counselling skills when working in this field. Counselling skills and the therapeutic relationship are described as critical for meeting the emotional needs of a client (Mortimer et al., 2009; Mossman, MacGibbon et al., 2009). By drawing on the concept of counselling skills in social work practice, Staniforth and Booysen (2016) have been able to show that these micro-skills are utilised in many fields of practice. The therapeutic relationship that grows through the use of these micro-skills is seen as the principal element of the healing process (Mortimer et al., 2009; Murphy et al., 2011; Thorburn, 2015).

\section{Knowledge}

The literature is saturated with recommendations for specialist training, education and specific qualifications in sexual violence work (Campbell et al., 2001; 
Ministry of Women's Affairs, 2009; Mortimer et al., 2009; Mossman, MacGibbon et al., 2009; Thorburn, 2015). Thorburn (2015), for example, suggests the importance of receiving training in dealing with power and control for workers in this field. This is echoed by Pack (2011) who highlights the need for social workers to acknowledge existing power dynamics when working with people who have experienced sexual violence. Other knowledge that could be included in specialist training and education relate to the factors that influence an individual's decision to disclose, the impacts of sexual violence, effective intervention skills, and theoretical frameworks that underpin practice (Murphy et al., 2011; Thorburn, 2015).

Several studies indicate that service delivery in the field of sexual violence has a theoretical underpinning from feminist (Jordan, 2013; Jülich, Sturgess, McGregor, \& Nicholas, 2013; Mossman, Jordan et al., 2009; Pack, 2011; Thorburn, 2015) and trauma-informed perspectives (Mason \& Lodrick, 2013; Mortimer et al., 2009; Murphy et al., 2011; Pack, 2011; Stenius \& Veysey, 2005; Thorburn, 2015; Wharewera-Mika \& McPhillips, 2016). By drawing on feminist theory, Jordan (2013) makes historical links between language use, social justice and political activism within the domain of sexual violence. Similarly, Thorburn (2015) argues that this field has been traditionally influenced by feminist empowerment principles and observes that these principles are still present in practice. Commenting on trauma-informed practice, Mortimer et al. (2009) suggest the expectation professionals have of one another in the sexual violence field is to have a sound theoretical grounding in trauma. This view is supported by Thorburn (2015) who writes that trauma theories should be integrated into sexual violence training due to the specialist nature of sexual trauma. Together, these studies support the notion that feminist and traumainformed perspectives and comprehensive and specialist knowledge is foundational for good practice social work.

\section{Values}

The values that contribute to good practice social work in the sexual violence field have been discussed throughout the literature and include self-determination and the worth and dignity of clients. Jordan (2008) reminds us that it is necessary to respect a client's positioning because positive impacts emerge when professionals accept and respect the needs and wants of the client. In a similar vein, the Ministry of Women's Affairs (2009) discusses self-determination through the framework of client-focused service delivery. This view is also supported by Murphy et al. (2011) who write that social workers must keep pace with the client and follow their lead. The concept of choice is also addressed at length in the literature. Stenius and Veysey (2005), for example, write that choice is crucial including creating space for clients to make their own decisions around the pace at which they heal, what issues they want to work on, and who they want to work with. They discuss that attention needs to be paid to what the client is requesting as this aids in preserving the self-determination of the client, and may also increase the person's sense of control. Jülich et al. (2013) also point out that a client-centred approach involves giving relevant options and respecting the options that are chosen.

The valuing of the worth and dignity of clients should be prioritised especially in meeting cultural needs. This perspective recognises that female Māori and minority groups are more at risk of experiencing barriers to accessing appropriate services (Mossman, MacGibbon et al., 2009). Mossman, MacGibbon et al. (2009) note the importance of culturally appropriate services, which is supported by Mason and Lodrick (2013) who recognise that cultural and religious considerations may have significance for the healing journeys of the people accessing a service.

\section{Impacts of sexual violence}

Previous research has focused on the impacts that sexual violence has on both 
the individuals who have experienced this violence, and the professionals working within the field of practice. On an individual level, this may include a substantial sense of loss, including the loss of trust, control and sense of safety (Jülich et al., 2013; Ministry of Women's Affairs, 2012; Mortimer et al., 2009; Murphy et al., 2011; Thorburn, 2015). The psychiatric diagnoses of anxiety and post-traumatic stress disorder (PTSD) are mentioned repeatedly throughout the literature as common responses to experiencing sexual violence (Mason \& Lodrick, 2013; Mortimer et al., 2009). Guilt and shame are also referenced as major impacts on the individual that can intensify negatively when not responded to in a specialised way (Mortimer et al., 2009; Mossman, MacGregor et al., 2009;

Thorburn, 2015).

For the professional, working in the field of sexual violence may be a contributor to secondary or vicarious trauma, terms which, in this article, will be used interchangeably (Jirek, 2015; Temitope \& Williams, 2015). This may result in the social worker experiencing PTSD symptoms which can compromise their ability to provide high quality intervention for their clients (Michalopoulos \& Aparicio, 2012). Jirek (2015) points out that secondary trauma can also lead to a change in the social worker's world view, causing them to develop a more cynical outlook and lose their sense of hope. Social workers with heavy caseloads in this field are at a higher risk of experiencing secondary trauma (Temitope \& Williams, 2015). That risk may, however, decrease as a social worker becomes more experienced (Hargrave, Scott, \& McDowell, 2006).

Research on the impact of a social worker's personal trauma history on their risk of experiencing secondary trauma is varied. A study completed by Michalopoulos and Aparicio (2012) found no correlation between personal trauma history and secondary trauma, whereas Way, VanDeusen, and Cottrell (2007) found that having a personal trauma history increases the risk of experiencing secondary trauma. Michalopoulos and Aparicio (2012) suggest that protective factors against secondary trauma for social workers in the field of sexual violence include regular high quality supervision, continuing professional development, and social supports. Some social workers may also find processing and debriefing with their colleagues cathartic (Jirek, 2015).

\section{Method}

The aim of this study was to explore social workers' perceptions of good practice social work in the sexual violence field. A qualitative approach was deemed the most appropriate methodology given the focus on exploring individuals' unique experiences and perspectives (Ryan, Coughlan, \& Cronin, 2007).

Ethical approval from Massey University was granted under the low-risk category. Particular consideration was given to potential issues around conflict of interest and coercion due to the first author's engagement in the field of practice under examination. To remove any possible sense of obligation by participants, the participant criteria included the condition of not being known to the researcher. No agencies in the region where the author lived were approached. Consent was obtained in writing. While anonymity could not be guaranteed, confidentiality was ensured through the use of pseudonyms and exclusion of any identifying information.

Five agencies listed on the National Collective of Rape Crisis and Related Groups Aotearoa (http:/ / www.rapecrisisnz.org.nz/) website were emailed letters of invitation requesting that an information sheet and interview schedule were forwarded to social workers who met the participation criteria. The criteria included being a qualified social worker, having at least one year of experience in the sexual violence field, having access to Skype for the purpose of an 
interview, and not being previously known to the researcher. Interested participants were encouraged to contact the researcher directly. Five social workers who expressed interest in the research and met the criteria were interviewed.

Over the period June-August 2018 the first author interviewed two of the social workers in person and three by Skype. These semistructured interviews were conducted with one individual and two sets of pairs due to the preference of the participants. The social workers were all currently employed in organisations providing specialist services to people who have experienced sexual violence. The participants were asked for their perspectives on good practice social work in the sexual violence field, including the key contributing skills, knowledge and values.

The interview data were thematically analysed to identify themes and patterns (Braun \& Clarke, 2006; Vaismoradi, Turunen, \& Bondas, 2013). After the interviews were transcribed, the first author read the transcripts closely, identified recurring thoughts and ideas, then grouped those ideas to form themes. Following usual qualitative processes, the identified themes were then used to explore the similarities and differences in the perspectives of the participants.

\section{Findings}

Participants described their roles as multifaceted and complex involving a wide range of practice including psychoeducation, practical support, advocacy, and long-term therapeutic work. Due to the sophisticated level of social work practice considered necessary within the sexual violence field, they emphasised their social work skills, knowledge, and values extended beyond that of generic social work. Upholding boundaries was viewed as a primary responsibility and self-care for social workers was also considered crucial. These themes are discussed below.

\section{Skills, knowledge and values}

Participants identified a substantial selection of skills, knowledge and values necessary for social work practice in this specialist field. Therapeutic and relational skills were deemed of high importance due to the differentiation from generalist social work seen within this field of practice. Having the skills to work as a team through the use of a multidisciplinary approach was also considered to be essential. Developing specific sexual violence knowledge was raised by all participants, as well as their concern around limited sexual violence training for social workers. Participants acknowledged patience as a fundamental value while also highlighting the importance of balancing hope against the discouragement that social workers can face within this field.

\section{Skills}

The evolution of the role of the social worker in the sexual violence field was described by the participants as having moved from a short-term crisis focus to a comprehensive holistic approach. Social work practice then was seen to have expanded into a multifaceted, long-term practice.

There's a huge skill set that's required actually as it's a fairly sophisticated level of social work. And it involves everything from making safe, psycho-education, practical supports, advocacy through to therapy sometimes. (SW 1)

Conversely, the participants suggested sexual violence social workers contracted by the Accident Compensation Corporation (ACC) may have a more restricted scope, with ACC considering "social work as more of a community type role where you will take someone to a WINZ [Work and Income New Zealand] appointment and take them home" (SW 3).

The fundamental social work skills of listening, having empathy, counselling and 
assessment were emphasised by participants. Having the skills to normalise and validate the client's feelings was highlighted and attention was paid to the skill of being nonjudgemental:

We are working with people who have been judging themselves long enough, they've been judged by others long enough, and you've got to be so careful because they are absolutely hypersensitive to any kind of emotional response that you give. So we've got to be able to understand that and being open minded and non-judgemental are absolutely baseline things. (SW 2)

Participants suggested that the decrease in capacity of counsellors in the sexual violence field has meant that social workers may work alongside clients for extended periods, focusing on both practical and therapeutic methods of practice. The therapeutic work is "highly relational" and the skills for working in a comprehensive therapeutic manner, rather than working primarily in a practical and transactional way, were described as essential for social workers in this field. What this has meant in practice is that social workers may engage in psychosocial support, psychoeducation, and the management of the client's trauma responses. The social workers, however, sometimes felt they needed to justify their skills and knowledge:

Because a lot of people define social work as all about practical stuff, all about finances. But I have to point out, you don't do a four-year degree to just go to WINZ, it's a lot more than that. And we actually do learn counselling skills, and we do that stuff. But I really struggled to have to justify that and figure out the context of the work that we're doing, because its crossing way past the practical stuff. (SW 2)

For some participants, utilising these skills in practice has meant challenging the understandings of other professionals about the scope of social work practice.

Participants suggested that teamwork approaches also assist in the creation of a therapeutic environment. While they acknowledged that the social worker is often the first person a client may see within their agency and might, therefore, be the initial person the client is disclosing their experience to, they also highlighted the importance of other agency staff:

But when a client comes in here, I always say right from the start really, they are a client of the agency, so individual counsellors don't have ownership over them, they don't own that client, that client is a part of this agency and so we all invest in the progress of that client and the outcomes of that client to a certain degree. (SW 4)

In particular, participants emphasised the importance of social workers having the skills to collaborate with counsellors. Recognising the strengths different professionals bring to the client interaction was seen to encourage better client outcomes.

\section{Knowledge}

Several theoretical frameworks were identified by participants as underpinning social work practice in this field such as strengths-based, solution-focused, taskcentred, Te Whare Tapa Whā, manaenhancing, systems, and attachment theory. Being flexible, adapting to meet the needs of individual clients, and using an eclectic approach were highlighted. The ecological systems of the clients were recognised by the participants with strong community relationships and a knowledge of government structures emphasised as crucial for enabling positive client outcomes:

A lot of these clients are, they continue to be put down, belittled, we're dealing with systems that are geared up towards doing 
that like WINZ, Oranga Tamariki, sort of everywhere they go there's still that real feeling of powerlessness. (SW 2)

Further, specific knowledge about sexual violence was considered crucial for good social work practice. This knowledge included understanding the impacts of sexual violence, trauma-informed practice, power and control, and neuroscience:

Knowledge of brain development, knowledge of emotional regulation, some of the more detailed aspects of central nervous system regulation, and what that looks like, that's really important when you're doing trauma work. (SW 4)

Despite these skills, knowledge and values being highlighted as important, there was a concern about the limited available training. This included both in the initial qualifying training programmes and ongoing professional development opportunities. While some training may focus on generic trauma, the participants believed there was limited availability of training on the specialist nature of sexual violence. According to the participants, this gap in relevant training might result in some agencies not employing newly qualified social workers or taking practicum students.

There was a concern among participants about the current training and qualifications not adequately addressing the needs of the professionals. While participants acknowledged training focused primarily on dealing with an initial sexual violence disclosure, they argued that they already "are the ones dealing with the disclosures" (SW 2). Some participants felt that the social work curriculum lacked adequate focus on trauma-informed practice, thus leaving qualified social workers with a knowledge gap. Participants suggested these gaps could be best addressed by an online course as this would be accessible for social workers throughout Aotearoa New Zealand. They also recommended using experienced clinical managers to act as mentors and assist with building the knowledge and skill base of a clinical team within an agency.

\section{Values}

The value of patience in regard to respecting the client's experience was expressed by all participants. They discussed the social worker role as supporting each client in their individual journey, remaining non-judgemental of their choices, and assisting them to navigate their problems on their own terms. The importance of allowing space for the client to lead the journey, and for the social worker to keep at their pace because "it's their journey, it's their story, it's their way" (SW 3) was a consistent message.

Social justice was also identified as a key value by participants, however, they cautioned that the push for social justice should not dominate the client's wants and needs. Another value that was of significance was the belief in the "good". Acknowledgement was given to the nature of sexual violence social work and how "you could begin to view the world through a particular lens and only through that lens. So, holding hope is really important, but also that belief in the intrinsic good within people" (SW 4). Hope, therefore, was also of importance.

\section{Boundaries}

Boundaries were discussed as the responsibility of the social worker; however, these might not always be rigid. Some boundary flexibility, for example, might be acceptable when a social worker is working holistically; such as when the client needs "connection", then it would be appropriate to give the client a hug.

Therapeutic social work was also highlighted as a space for having flexibility in boundaries. The flexibility was seen as dependent on the skill level of the individual 
social worker, as it is the responsibility of the social worker to remain ethical by working within their scope and competence:

Again it's about being very aware of your boundaries and knowing when to stop, when you've reached the outer limits of what your scope or knowledge set is and if you're going into deeper therapeutic work then that belongs with the people who've got the skills and training and understanding of that. (SW 4)

Participants believed that other professionals felt that only counsellors could carry out therapeutic work while social workers focus on practicalities, and opposed this apparent divide. Increasing opportunities for teamwork across professions was proposed as one way to navigate this boundary while keeping the scope of social work in this field from narrowing. Mutual respect was emphasised: "we're not threatened by each other; I think that's part of the thing. We respect each other's professional skills and judgements" (SW 2). Participants said having boundaries assists the social worker in working within their scope and being clear about their role. Participants identified holding boundaries as significant to the work they do with clients as using their own boundaries can be a way to teach clients how to set boundaries for themselves:

In the work that I do with people, a lot is about boundary setting for them. Because their boundaries have been so violated across time, they really struggle to understand what the line is. (SW 2)

Maintaining a reflective and boundaried practice can also assist the social worker in avoiding rescuing behaviours, which could be particularly harmful in the context of sexual violence:

So, some really good self-awareness around boundaries and the realisation that you can't always make everything ok, you can do what you can to make things, you can ameliorate difficulties in people's lives and you can equip them and empower them with some tools to cope with what life throws at them but very seldom can you make everything ok. (SW 4)

The ability to employ professional and personal boundaries was also described as a way to enhance client-centred practice. When a social worker fails to maintain those boundaries there may be a risk that "you're starting to stray a little into your own stuff and you can lose sight of what it is the victim actually needs in that moment" (SW 4).

\section{Self-care}

Self-care was a recurring theme from participants. Self-care was discussed in relation to the difficult nature of sexual violence work with an emphasis on the impact of traumatic content on social workers:

Because sometimes you do hear about stuff that's traumatic to yourself, so that's secondary trauma, so making sure that you're aware of that. Making sure that you do discuss things like that. (SW 3)

While some participants acknowledged the importance of collegial support, there was a belief that regular supervision with an experienced practitioner was essential for self-care. Different forms of supervision including internal, external and peer were deemed valuable. Additionally, utilising cultural supervision within a non-kaupapa Māori agency was considered important due to the high number of Māori clients using the services.

Due to the sensitive nature of sexual violence and the current climate of heavy social work caseloads, self-care in this field was viewed as not only the responsibility of individual social worker, but also of the agency:

I suppose that over 30 years we've learned a thing or two about how to "hold" / look after people who work here. 
No one is allowed to work here full time and we have a lot of supports around people. There's a lot of team work and a lot of supervision and guidance. We're pretty clear that you burn people out really quickly if you give them ridiculous workloads with such intense stuff, so the wrap around is really important from the agency. (SW 1)

Boundaries could also be set by individual social workers to sustain their self-care practices. This included having regular working hours and refraining from working overtime. Learning to say "no" was also advised in order to avoid becoming saturated in the work. Maintaining the difference between sympathy and empathy was seen as imperative because, "you can take on too much of that emotional baggage. You've got to be able to be empathetic without taking on their stuff" (SW 2). While this may be common practice for social workers, the participants reiterated the point due to the possibility of secondary trauma and the overall nature of working in the sexual violence field.

Another common social work practice that was highlighted as a boundary to assist in self-care was that of separating one's personal and professional lives. One participant felt that their own personal and professional lives were intertwined before entering the sexual violence field. They discussed how they had built up the boundary between their personal and professional lives by not watching violent movies or television shows, and also by creating boundaries around their community presence to ensure the confidentiality of those within the community who were accessing the specialist service.

Importantly, self-awareness around personal triggers and potential danger that comes with working in this field without having completed personal work first was emphasised by all of the participants, as illustrated in this comment:
If we're not fully aware of what our own stuff is, and we haven't dealt with it, we can do a lot of harm to people and to ourselves. You can do a lot of harm to yourself in this field if you're triggered by things. (SW 2)

Given the importance of excellent self-care practice, someone who has had a very recent experience of sexual violence might not be in the right space for working in this field.

\section{Discussion}

Sexual violence is a complex, sophisticated and specialised field of practice for social workers. The participants emphasised that this area of social work practice exceeded that of crisis intervention and practical support, and therefore requires an extensive skill set. Minimal literature on the scope of social work practice in the sexual violence field is available although some Aotearoa New Zealand literature has addressed the practice of social workers in this area, but only in the context of them working as therapists (Pack, 2011).

There appears to be an increasing need for specialist sexual violence services (Whareware-Mika \& McPhillips, 2016). With limited capacity for counselling services, social workers might be required to upskill and work more therapeutically. Therapeutic social work and the therapeutic relationship were identified as key components of social work practice in this field. The therapeutic relationship is foundational to sexual violence work and is essential for positive outcomes (Accident Compensation Corporation (ACC), 2008; Mortimer et al., 2009; Murphy et al., 2011). This finding suggests that there is overlap between social work and counselling practices, which is consistent with Staniforth and Booysen (2016) who recognised that many social workers in Aotearoa New Zealand use counselling skills or engage in counselling practice within their social work practice. 
Listening is a critical social work skill, as it enables the practitioner to understand the needs of the person they are supporting. Using acceptance to manage the tensions between one's worldview and professional practice can have a positive impact on the potential guilt and shame felt by the person who experienced the sexual violence. Similarly, previous studies that focused on universal sexual violence work also emphasised validating and normalising the feelings of someone who has experienced sexual violence, thus leading to the person gaining the ability to move away from the feelings of guilt and shame (Mortimer et al., 2009; Mossman, MacGibbon et al., 2009; Murphy et al., 2001; Thorburn, 2015). Practising in a non-judgemental and accepting way creates the foundation for trust and safety within a client's healing process (Mortimer et al., 2009).

Having the skills to collaborate as a team member, across disciplinary boundaries, is an integral part of good practice for social workers. Integrated, wrap-around services are also identified as essential for good practice in the sexual violence field and the role of social workers in this space could benefit from further recognition and understanding. An individual who experiences sexual violence may have varying levels of need over time and so counselling and social work practitioners, as well as other professionals, should continue to discover effective ways to work alongside one another to better support their clients (Whareware-Mika \& McPhillips, 2016). Agency-wide participation in creating a therapeutic environment is an important team approach to practice. The environment of specialist support services can have a direct impact on the well-being of the person accessing the service (ACC, 2008; Mossman, Jordan et al., 2009). This can include the physical environment, as well as the environment created by the interactions between staff and clients (WharewareMika \& McPhillips, 2016). Agency-wide investment in positive client outcomes is foundational to good practice.
An important, but perhaps obvious, finding to emerge from the analysis in this study is that sexual-violence-specific knowledge is essential for social work in this field. The necessity of knowledge around the impacts of sexual violence, the brain's response to trauma, power and control, and trauma-informed practice discussed by the participants is congruent with previous studies and further supports the idea that sexual violence is a specialised field of practice requiring specialised knowledge (Murphy et al., 2011; Pack, 2011; Thorburn, 2015). Another interesting finding was that, while the literature highlighted feminist theory as central to sexual violence work (Jordan, 2013; Jülich et al., 2013; Mossman, Jordan et al., 2009a; Pack, 2011; Thorburn, 2015), participants did not identify any theories of gendered violence as significant to their practice.

The values of patience and keeping pace with the client was highlighted as significant to sexual violence social work practice. These results further support the idea of selfdetermination and client choice (Ministry of Women's Affairs, 2009; Murphy et al., 2011). The notion of hope was also reported by participants as a core value in this field, which is consistent with that of Jirek (2015) who discussed the potential loss of hope and change in world view that can arise from secondary trauma. Social justice was also identified as an essential value, resonating with previous research and the global definition of social work (Pack, 2011).

Creating and maintaining boundaries in this field were seen to be significant. Boundaries were described as a tool for social work intervention; some people who have experienced sexual violence face a loss of trust and safety (Ministry of Women's Affairs, 2009; Mossman, MacGibbon et al., 2009) and teaching them about boundaries can assist in the development of their interpersonal relationships. Boundaries are also significant to a social worker's role, so as to ensure rescuing behaviour and dependence is avoided (ACC, 2008). Despite 
this, there is an absence of research directly linking boundaries to this field of practice for social workers.

The current study confirmed that self-care is significant to good practice social work in the sexual violence field. This finding is aligned with other research that found that working in the sexual violence field can have serious impacts on the worker, such as secondary traumatisation and emotional fatigue (Whareware-Mika \& McPhillips, 2016). Self-care also includes personal awareness around one's own triggers and creating space between the social worker and their own personal experience of sexual violence. This finding suggests that personal therapy or healing may be a requirement of social workers practising in the sexual violence field who have had their own experiences of sexual trauma. Personal trauma treatment may then decrease the risk of experiencing secondary trauma (Way et al., 2007).

Social workers are encouraged to utilise multiple types of supervision including external clinical, internal, peer supervision or collegial support. Pākehā and Tauiwi social workers working with Māori should be engaging with cultural supervision to ensure culturally responsive and safe practice (Whareware-Mika \& McPhillips, 2016). Other recent studies have also indicated that consistent high quality supervision and collegial debriefing lower the risk of secondary traumatisation (Jirek, 2015; Michalopoulos \& Aparico, 2012).

Many studies have called for the creation of specialist training, education and qualifications for work in the sexual violence field of practice (Campbell et al., 2001; Ministry of Women's Affairs, 2009; Mortimer et al., 2009; Mossman, MacGibbon et al., 2009b; Thorburn, 2015). Surprisingly then, there is a lack of training, courses and qualifications focused on sexual violence social work in Aotearoa New Zealand and the training programmes that do exist may not be meeting the needs of frontline social workers. Specialist sexual violence training should incorporate, not only disclosures and the impacts of sexual violence, but also a robust examination of the theoretical approaches and the most effective social work interventions for this field of practice (Ministry of Women's Affairs, 2009; Mortimer et al., 2009; Murphy et al., 2011; Pack, 2011; Thorburn, 2015).

It is recommended to future researchers and educators that the scope of practice for sexual violence social work be identified and included in a general or stand-alone qualification, and that the role of social workers in this field and how they determine their scope of work be further explored through research.

Due to the small number of participants in the research, the findings cannot be generalised or viewed as a representation of all social workers in the sexual violence field of practice (Ryan et al., 2007). Nevertheless, the research provides insights into the perspectives of social workers in the field of sexual violence. The predominantly female influence within the study was also a limitation; an increase in gender diversity may have yielded different findings. Another limitation is the use of Skype during the data collection; connection issues may have limited the natural flow of the interview and could have caused important data to be missed.

\section{Conclusion}

Good practice social work in the sexual violence field is critical for the wellbeing of people who have experienced sexual violence. As a specific scope of practice, limited attention has been given to the personal and professional development needs of social workers working in this area. Further attention to specialised training opportunities including in boundary setting, self-care, and skills and knowledge will strengthen current practice. Furthermore, with the high prevalence of sexual violence in Aotearoa New Zealand and the current social climate, sexual violence social work is an important topic for future research. 


\section{References}

Accident Compensation Corporation (ACC). (2008). Sexual abuse and mental injury: Practice guidelines for Aotearoa New Zealand. Wellington, NZ: Author.

Braun, V., \& Clarke, V. (2006). Using thematic analysis in psychology. Qualitative Research in Psychology, 3(2), 77-101.

Campbell, L. (2016). Sexual assault support service for Canterbury: Research to inform service design. Christchurch, New Zealand: Aviva Family Violence Services.

Campbell, R., Wasco, S., Ahrens, C., Sefl, T., \& Barnes, H. (2001). Preventing the "second rape": Rape survivors' experiences with community service providers. Journal of Interpersonal Violence, 16(12), 1239-1259.

Fanslow, J., Robinson, E., Crengle, S., \& Perese, L. (2007). Prevalence of child sexual abuse reported by a crosssectional sample of New Zealand women. Child Abuse \& Neglect, 31(9), 935-945.

Hargrave, P., Scott, K., \& McDowell, J. (2006). To resolve or not to resolve: Past trauma and secondary traumatic stress in volunteer crisis workers. Journal of Trauma Practice, 5(2), 37-55.

Jirek, S. (2015). Soul pain: The hidden toll of working with survivors of physical and sexual violence. SAGE Open, 5(3), 1-13.

Jordan, J. (2008). Serial survivors: Women's narratives of surviving rape. Annandale, NSW: Federation Press.

Jordan, J. (2013). From victim to survivor-and from survivor to victim: Reconceptualising the survivor journey. Sexual Abuse in Australia \& New Zealand, 5(2), 48-56.

Jülich, S., Sturgess, C., McGregor, K., \& Nicholas, L. (2013). Cost as a barrier to recovery: Survivors of sexual violence. Sexual Abuse in Australia \& New Zealand, 5(2), 57-68.

Mason, F., \& Lodrick, Z. (2013). Psychological consequences of sexual assault. Best Practice \& Research Clinical Obstetrics \& Gynaecology, 27(Clinical Aspects of Sexual Violence), 27-37. doi:10.1016/j.bpobgyn.2012.08.015

Mayhew, P., \& Reilly, J. (2009). The New Zealand crime and safety survey 2006. Wellington, NZ: Ministry of Justice.

Michalopoulos, L., \& Aparicio, E. (2012). Vicarious trauma in social workers: The role of trauma history, social support, and years of experience. Journal of Aggression, Maltreatment \& Trauma, 21(6), 646-664.

Ministry of Women's Affairs. (2009) Restoring Soul: Effective interventions for adult victim/survivors of sexual violence. Wellington, NZ: Author.

Ministry of Women's Affairs. (2012). Lightning does strike twice: Preventing sexual Revictimisation. Wellington, NZ: Author.

Mortimer, R., Gillian, C., Woolley, C., Campbell, J., Harvey, S., Taylor, J., \& Dickson, J. (2009). Survey of practitioners providing therapy for survivors of sexual abuse/assault in Aotearoa/New Zealand. New Zealand Journal of Counselling, 29(1), 54-72.

Mossman, E., Jordan, J., MacGibbon, L., Kingi, V., \& Moore, L. (2009). Responding to sexual violence: $A$ review of literature on good practice. Wellington, NZ: Ministry of Women's Affairs.
Mossman, E., MacGibbon, L., Kingi, V., \& Jordan, J. (2009). Responding to sexual violence: Environmental scan of New Zealand agencies. Wellington, NZ: Ministry of Women's Affairs.

Murphy, S., Potter, S., Pierce-Weeks, J., Stapleton, J., Wiesen-Martin, D., \& Phillips, K. (2011). Providing context for social workers' response to sexual assault victims. Affilia: Journal of Women \& Social Work, 26(1), 90-94. doi:10.1177/0886109910392529

Pack, M. (2011). Discovering an integrated framework for practice: A qualitative investigation of theories used by social workers working as sexual abuse therapists. Journal of Social Work Practice, 25(1), 79-93. doi:10.1080/02650533.2010.530646

Ryan, F., Coughlan, M., \& Cronin, P. (2007). Step-bystep guide to critiquing research. Part 2: Qualitative research. British Journal of Nursing, 16(12), 738-744. doi:10.12968/bjon.2007.16.12.23726

Staniforth, B., \& Booysen, P. (2016). Counselling training in social work in Aotearoa New Zealand. Are we there yet? Advances in Social Work and Welfare Education, 18(2), 24-38.

Stenius, V., \& Veysey, B. (2005). "It's the little things": Women, trauma, and strategies for healing. Journal of Interpersonal Violence, 20(10), 1155-1174.

Temitope, K., \& Williams, M. (2015). Secondary traumatic stress, burnout and the role of resilience in New Zealand counsellors. New Zealand Journal of Counselling, 35(1), $1-21$.

Thorburn, N. (2015). Training needs of sexual violence crisis workers. Advances in Social Work and Welfare Education, 17(1), 112-125.

Vaismoradi, M., Turunen, H., \& Bondas, T. (2013). Content analysis and thematic analysis: Implications for conducting a qualitative descriptive study. Nursing and Health Sciences, 15(3), 398-405.

Way, I., VanDeusen, K., \& Cottrell, T. (2007). Vicarious trauma: Predictors of clinicians' disrupted cognitions about self-esteem and self-intimacy. Journal of Child Sexual Abuse, 16(4), 81-98.

Wharewera-Mika, J., \& McPhillips, J. (2016). Guidelines for mainstream crisis support services for survivors (round two): Good practice responding to sexual violence. Wellington, NZ: Te Ohaaki a Hine-National Network Ending Sexual Violence Together. 